\title{
A sexualidade nos umbrais: entre Política e Psicanálise 136
}

\section{Paula Peron 137}

Há algum tempo trabalho supervisionando alunos de quinto ano do curso de graduação em Psicologia, em um núcleo de Psicanálise, na PUC/SP, em atendimentos psicoterápicos de orientação psicanalítica, com homens e mulheres transsexuais e outras múltiplas sexualidades, de algumas instituições de cuidado, saúde e assistência a população LGBTQ+ (a sigla mais completa é LGBTTQQIAAP lesbian, gay, bisexual, transgender, transsexual, queer, questioning, intersex, $\underline{\text { asexual/aromantic, }}$ agender, and pansexual), invariavelmente em condições de vulnerabilidades. Também supervisiono jovens analistas em suas formações, que trabalham com esta população.

Embasar este trabalho na Psicanálise parece-me perfeitamente possível, embora reconheça também que há uma certa lacuna entre a teorização desta prática e o trabalho clínico em si. Por isto aceitei participar desta mesa, porque me interessa permanecer em diálogo sobre as questões relativas à sexualidade na contemporaneidade, e as condições teóricas da Psicanálise.

Quanto a política, parto do reconhecimento da natureza interligada entre poder e sexualidade. Além disto, a direção de um tratamento e a finalidade dos atos do analista estão necessariamente articuladas ao papel da clínica na sociedade e, assim, estamos necessariamente implicados na política (por exemplo abandonamos a sugestão por sua produção de um poder soberano, que recusamos ocupar). Então me interessa pensar sobre a posição e o poder da Psicanálise na discussão sobre as sexualidades contemporâneas.

Estou também consciente da forte presença da militância política em prol desta população citada, e de muitas críticas que são dirigidas a Psicanálise a partir destes movimentos, bem como de movimentos feministas. Tomarei uma destas falas, a fala de Paul Preciado, feita na França em novembro de 2019, para provocar respostas das minhas posições psicanalíticas.

\footnotetext{
${ }^{136}$ Trabalho apresentado na mesa "A sexualidade nos umbrais: entre Política e Psicanálise" no II Simpósio Bienal SBPSP "Fronteiras da Psicanálise: a clínica em movimento" no dia 29 de agosto de 2020.

137 Doutora em Psicologia Clínica pela PUC-SP onde é professora de Psicologia, psicanalista do Instituto Sedes Sapientiae.
} 
Alguns de vocês talvez conheçam, mas retomarei brevemente a biografia e algumas ideias de Paul Preciado (dos livros Testo Junkie, Manifesto Contrassexual e Um apartamento em Urano), para enriquecer nosso diálogo. Depois disto, apresentarei pontos que destaquei da fala de Paul Preciado para a Escola de Psicanálise, e por último tento dialogar com alguns deles, para fazer avançar minha escuta clínica frente aos sofrimentos ligados à população LGBTQ+.

Paul B. Preciado, nascido Beatriz Preciado em 1970 na Espanha, é um escritor contemporâneo, filósofo e curador, cujo trabalho foca nas questões de identidade, gênero, arquitetura e sexualidade. Descreve-se como um dissidente do sistema sexo-gênero. Este pesquisador e professor de História Política do corpo, teoria do gênero e história da performance na Université Paris VIII nega o caráter biológico da transexualidade, ressaltando sobretudo o aspecto político e acentuando que a sexualidade é singular, móvel, difusa e múltipla. Ele afirma que o regime de gênero binário (homem-mulher, hetero-homo) faz controle político das sexualidades e aponta que nossas sexualidades são ficções discursivas. No entanto, enfatiza a presença dos corpos e a incorporação, a encarnação destas práticas discursivas. Como homem trans, afirma estar constantemente questionado sobre sua ficção sexual política, diferentemente das formas hegemônicas de sexualidade. Segundo ele, as ficções políticas de gênero (ser mulher, ser homem, ser trans) são sempre limitadas e apesar de serem formas de incorporação prostética, se fazem passar por naturais. Para ele, não há sexos, mas usos dos corpos, que são divididos entre os proibidos e aqueles considerados naturais, ou seja, definidos sempre em relação e não essencialmente. Afirma que tanto a masculinidade quanto a feminilidade estão sujeitas as tecnologias sociais e políticas de construção e de controle, assim, o sexo seria uma tecnologia biopolítica de controle dos corpos, instrumentos, usos e usuários sexuais.

Preciado tematiza a contemporaneidade através da forte noção de Farmacopornografia, regime onde a masturbação é incentivada, ao contrário do regime disciplinar moderno, onde era proibida. A sexualidade farmacopornográfica é produzida no fechamento do sujeito, governada pela imagem fantasiada e representada, e pela cadeia de excitação-frustração em que se baseia, sustentada por hormônios, que foram transformados em objetos de 
consumo, e através deles, controla-se as definições sexuais dos sujeitos (por exemplo, ser mulher $=$ ser consumidor de pílula anticoncepcional). Preciado fala em uma dissolução de tais tecnologias no corpo, tornam-se parte dele (somatecnics), e afirma que "não há corpo humano universal, mas uma multiplicidade de seres humanos e tecidos orgânicos racializados, sexualizados, generificados" (Testo Junkie, p. 170), ficcionalizados somaticamente em homens e mulheres, embora iludidos de serem resultantes de leis transculturais, transhistóricas, imutáveis e naturais. Considera que as relações sexuais supõem relações de poder assimétricas e naturalizadas, e coloca-se fortemente contra as políticas psiquiátricas, médicas, administrativas e jurídicas envolvidas nas mudanças de sexo.

Este pensador apresenta-se em 17 de novembro de 2019, no âmbito da $49^{\mathrm{a}}$ Jornada da Escola da Causa Freudiana (fundada em 1981 e signatária da Associação Mundial de Psicanálise): "Mulheres na psicanálise". Ele saúda os participantes, e diz-se certo de que entre eles não há nenhum não binário, ou mutante como prefere dizer, ou alguém que tenha renunciado a diferença sexual. Aponta que como transexual, é caracterizado pela maior parte das teorias psicanalíticas como para além da neurose; à beira, ou mesmo dentro, da psicose; tendo uma incapacidade de resolver corretamente um complexo de Édipo ou havendo sucumbido à inveja do pênis. Ele aponta que causa espanto organizar um encontro para falar das "mulheres na psicanálise" em 2019 como se nós ainda estivéssemos em 1917 e a mulher não tivesse um reconhecimento pleno enquanto sujeito político.

Afirma que o regime da diferença sexual com o qual a Psicanálise trabalha não é nem uma natureza, nem uma ordem simbólica, mas uma epistemologia política do corpo; e que, como tal, é histórica e mutável. E que esta epistemologia binária e hierárquica está em crise desde os anos 1940, não somente por causa da contestação exercida pelos movimentos políticos de minorias dissidentes, mas também em função do surgimento de novos dados morfológicos, cromossômicos e bioquímicos que tornam impossível a atribuição sexual binária. Defende que a epistemologia da diferença sexual está em mutação, e vai ceder lugar a uma nova epistemologia. O movimento transfeminista, queer, de denúncia da violência heteropatriarcal, mas também as novas práticas de filiação, de relação amorosa, de identificação de gênero, de desejo, da sexualidade e da nomeação são indícios 
dessa mutação. Preciado prossegue afirmando que a Psicanálise, vista do ângulo da história dos corpos abjetos, da história dos monstros da sexualidade normativa, é a ciência do inconsciente patriarcal e colonial. Pede que não tentemos negar a cumplicidade da Psicanálise com a epistemologia da diferença sexual heteronormativa, que consumiria a energia psíquica dos sujeitos para produzirem suas identidades normativas. A Psicanálise não seria uma crítica dessa epistemologia dominante, mas sim a terapia necessária para que o sujeito patriarcal-colonial continue funcionando, apesar dos custos psíquicos enormes da violência indescritível desse regime. Apresenta a hipótese de que Lacan não conseguiu se desfazer do binarismo sexual por causa da sua afeição política pelo patriarcado heterossexual. A sua desnaturalização está conceitualmente em marcha; mas Lacan, ele próprio, não estava pronto.

Preciado considera insustentável continuar afirmando a universalidade da diferença sexual e a estabilidade das identificações heterossexuais e homossexuais numa sociedade onde é possível mudar de sexo, onde é possível se identificar como pessoa de gênero não binário; numa sociedade em que já há milhares de crianças nascidas em famílias não heterossexuais e não binárias. Continuar praticando a Psicanálise utilizando a noção de diferença sexual, e com instrumentos críticos como o complexo de Édipo, seria hoje, para Preciado, tão aberrante como pretender continuar navegando pelo universo com um mapa geocêntrico ptolomeico, ou negando as mudanças climáticas, ou afirmando que a Terra é plana.

Meu interesse por Preciado e suas ideias e práticas instigantes não me permite descartar esta fala dura apressadamente, em defesa do Édipo e da Psicanálise. Penso que há inúmeras questões aqui para desdobrarmos, e acho que elas podem somente nos chegar desde fora, desde a filosofia, neste caso.

Concordamos em muitos pontos - que a sexualidade é múltipla e disruptiva, que as identidades homem e mulher são construídas socialmente, ou na relação com o Outro. Estou segura de que podemos assumir a heterossexualidade não como um ímpeto biológico, mas sim como um dos resultados incertos de um longo processo de destino libidinal e agressivo, e que qualquer gênero pode ser resultante de inibições e sintomas, cujas bases teóricas Freud apresenta nos Três ensaios sobre a teoria da sexualidade. Concordo com Coutinho Jorge que afirma sobre os Três ensaios: "é uma obra cuja atualidade é enorme. Nela, Freud 
estabelece as bases da concepção psicanalítica da sexualidade e produz uma subversão cujo alcance político se estende por todo o século XX" (Coutinho Jorge, p. 17). Há em tal texto um corte epistemológico de amplo alcance nos estudos da época e Freud trabalha para descaracterizar o binarismo normalidade/patologia (um binarismo que deveria nos preocupar), nas palavras de Freud: a "disposição para as perversões de toda espécie é uma característica humana geral e fundamental"(p.174). Se é verdade que, por um lado, Freud trabalhou muito para separar certas condições psíquicas do campo do psicopatologia, para questionar o campo da dita normalidade, e, portanto, da legislação e gerenciamento médicos, por outro lado, como afirma Pedro Ambra, a psicanálise é não-toda subversiva, já que opera uma subversão radical na clínica, mas mantém um saber muitas vezes fixo (Ambra, 2016). Reconheço isto na minha própria e na prática clínica dos colegas - por enfatizarmos as singularidades, a ética do sujeito e a constituição identificatória, libidinal e agressiva do sujeito (ainda que a fixidez desta possa ser questionada), somos capazes de escutar e analisar as multiplicidades de configurações sexuais, mas será que produzimos uma ética do cuidado que consegue se desembaraçar dos limites teóricos e não patologizar as configurações sexuais menos dominantes? Somos psi-safe? Brevemente, trata-se de uma plataforma digital francesa que inclui psicanalistas que são tidos como conscientes das dimensões sociais de opressão e sofrimento que incidem sobre as sexualidades não dominantes (aqui há todo um problema relativo a identidade sexual do analista - um paciente gay que pede um analista gay porque acha que ali se sentirá melhor ouvido - assunto para outra conversa. Apenas para deixar apontado, procurar um analista gay não significa que ele será melhor analista para você do que um analista hetero, mas quando os analistas heteros escolhem analistas, pensam sim se querem um homem ou uma mulher, provavelmente tomando-os por heterossexuais, e isto não é irrelevante na transferência, especialmente para o seu estabelecimento). Mas voltando ao ponto, somos capazes de reconhecer as dimensões sociopolíticas do sofrimentos destes sujeitos? E podemos pensar a psicanálise, em suas teorizações e nomenclaturas, como participantes das causas dos sofrimentos?

Acho que estamos longe de assumir posições teóricas que espelham uma mudança mais radical em algumas de nossas premissas teóricas que são compreendidas como reforçadoras de poderes patriarcais - isto envolve mais do 
que "mudar a proporção do cuidado da criança conduzido pelos homens e pelas mulheres; envolve mudar as estruturas materiais e simbólicas que determinam como o desejo é socializado" (Frosh, p. 210).

Geralmente pressupomos sim que os destinos são homem e mulher, e falamos destes destinos no singular, e outros destinos seriam desvios destes que, embora não anatômicos, estão bastante marcados/valorizados em nossas teorias, ainda que não os pensemos como substâncias fixas e idênticas a si mesmas. Provavelmente Preciado tem razão ao afirmar que ainda não respondemos de forma mais ampla a segunda onda do feminismo (50/60), como os gender studies e toda sua produção nos anos 80 e 90 (Com Butler como exemplo, que pode oferecer uma interlocução bastante revigorante para a psicanálise).

Uma outra filósofa nos ajuda a pensar impasses da psicanálise e a sexualidade, no contemporâneo, Alenka Zupancic (uma teórica da psicanálise e da filosofia, da Eslovênia, que ensina no European Graduate School e é pesquisadora no Institute of Philosophy at the Slovenian Academy of Sciences and the Arts). Ela ressalta que a sexualidade é precisamente onde o simbólico vacila, e enfatiza que a linguagem não dá conta das sexualidades, e que portanto não bastaria que colocássemos mais letras na sequência já longa LGBTQ+ para nomearmos as sexualidades, já que a sexualidade seria da ordem do inominável.

Também podemos pensar que a sexualidade é mais disruptiva do que construtora de identidades, e que portanto, não deveríamos apostar na caracterização de identidades. Este pensamento também nos leva a ideia, importante em Psicanálise, de que a sexualidade é imposta do ponto de vista inconsciente, e portanto a opressão não é apenas externa, mas também interna.

Quanto ao problema mais espinhoso do binarismo, podemos pensar que nossa noção de diferença sexual se sustenta principalmente como a impossibilidade do pleno encontro com o Outro. Nisto, a noção de objeto a em Lacan, e sua dimensão de impossibilidade e falta nos faz avançar. Há uma dimensão imaginária na diferença dos sexos e uma "falta estrutural de inscrição do objeto do desejo no inconsciente" (Coutinho Jorge, vol. 1, p. 35).

Portanto, não se trata da descrição pura e simples das diferenças entre homens e mulheres, mas do fato de que as relações sexuais são ilógicas e faltantes, e que precisamente isto nos abre para os laços sociais e para as multiplicidades sexuais, sempre vacilantes. 


\section{Referências}

PRECIADO, Paul B. (2019) Um apartamento em Urano (Conferência) [Trad. C. Q. Kushiner \& P. S. Souza Jr.]. Lacuna: uma revista de psicanálise, São Paulo, n. -8, p. 12, 2019. Disponível em: <https://revistalacuna.com/2019/12/08/n-8$12 />$.

PRECIADO, Paul B. Testo Junkie. São Paulo, N-1 edições, 2008.

PRECIADO, Paul B. Manifesto contrassexual. São Paulo, N -1 edições, 2000.

PRECIADO, Paul B. An Apartment on Uranus: Chronicles of the Crossing. 2019. Nova Iorque, Semiotext(e), 2020.

Checchia, Marcelo. Poder e política na clínica psicanalitica. São Paulo, Annablume, 2015.

Frosh, S. As políticas da psicanálise - uma introdução à teoria freudiana e pósfreudiana. São Paulo, Benjamin Editorial, 2019.

Dunker, C. Psicanálise sem gênero? In Assuar, G. Nunes, L., Pereira da Silva Jr., J. (orgs). Psicanálise, sexualidade e gênero - um debate em construção. São Paulo, Zagodoni Editora, 2019.

Ambra, P. O gênero endereçado: Butler, Lacan e Laplanche. In Assuar, G. Nunes, L., Pereira da Silva Jr., J. (orgs). Psicanálise, sexualidade e gênero - um debate em construção. São Paulo, Zagodoni Editora, 2019.

Jorge, M. A. C. Fundamentos da Psicanálise de Freud a Lacan. Vol.2: A clínica da fantasia. Rio de Janeiro: Zahar, 2010.

FREUD, S. The Standard Edition of the complete psychological Works of Sigmund Freud. Londres: The Hogarth Press, 1995.

Zupancic, A. What is sex? Cambridge, MIT Press, 2017. 